\title{
Application and Research of Automatic Chalk Holder
}

\author{
Jin Kui ${ }^{\mathrm{a}}$, Zhang Peng ${ }^{\mathrm{b}}$ \\ Dalian Vocational \& Technical College, China, 116037 \\ ajk_810912@163.com, bp1231@163.com
}

Keywords: chalk, holder design, automatic pen-out, easy to install, protect the skin

\begin{abstract}
Aiming at solving the shortcomings such as the bad stimulation of the chalk dust on the skin and the wastage of broken chalks during writing, this paper designed an automatic chalk holder with simple structure and good clamping performance in order to solve the problems such as the protection of teacher's hand skin from the chalk dust while writing on the blackboard and waste problems caused by chalk breaking when chalk is used with different writing strength. The above problems are solved by practical application of the automatic chalk holder.
\end{abstract}

\section{Introduction}

As we all know, in the field of education, chalk, as a teaching aid, is a necessary tool for the present education. It is used to impart knowledge and is one of the most primitive and traditional main teaching methods. With the progress of history and the development of society, people's understanding of chalk as a teaching aid has been improving. The chalk has made great contribution to human education, and also brought great harm to the health of teachers and students engaged in education. For example, teachers often need to write on the blackboard and drawing to explain. In a 40-minute lesson, teachers need to write and erase many times and after class, teachers often leave with a layer of chalk ash on their hands, sleeves, and even hair.

\section{The Necessity of Using Chalk Holder in Traditional Teaching}

In most schools or educational institutions, teachers generally use chalk to write on the blackboard and the knowledge to be conveyed is written on the board with chalk. Students take appropriate notes to absorb the knowledge so as to complete the teaching content and achieve the purpose of the instruction. However, during the teaching process, when teachers write on the blackboard with chalk, chalk dust will inevitably stick on the hand and stimulate the skin and mucosa .If chalk ash is decomposed by sweat, it produces alkaline substance, which is more irritating to skin and mucosa. By destroying the basic living environment of the skin, chalk ash will make the skin becomes dry, rough and accompanied by the feeling of itching. This will causes the human body unwell and even more, it can cause acne, hair follicle inflammation, and even the occurrence of finger cracks. In order to solve this problem, people have designed the chalk cover. The present chalk cover can be divided into two main types: one way is using the chalk sleeve. The chalk sleeve has a longitudinal groove and a clip sticking out from the longitudinal groove. The clip's end is inside the chalk sleeve and directly connected to the chalk. By pushing the clip, the chalk can be pushed outside of the chalk sleeve. The other way is the use of automatic pencil-type clamping and propulsion mechanism. This kind of chalk jacket structure is very complex and has many components. Because the propulsion component is at the end, it is not easy to push the chalk out during writing.

This article through the use of chalk holder in the teaching process of educational institutions to illustrate that the rational use of auxiliary tools can not only greatly improve the writing speed, but also overcome some shortcomings that occurred during the direct hand chalk writing. Such as fingers are easily fatigued because finger grip strength is heavy, chalk ash is easy to get clothes dirty and sticking on hand, and chalk is easily broken, resulting in waste. 


\section{Structure of Automatic Chalk Holder}

Automatic chalk holder is composed of: 1, gripper body, 2, Adjustment knob, 3, floating slider, 4, Spring, 5, taper hole, 6, straight groove, 7, Guide Groove, 8, Guide screw, 9, wear clip, 10, Elastic sleeve composition (Fig. 1).

It is characterized by: the main body of the gripper is a hollow cylinder structure, in which a floating slider is arranged inside the holder body, a spring is provided at one end of the main body of the gripper, a taper hole is provided at the other end of the floating slide, a straight groove and a guide groove are arranged on the surface of the floating slide, and a regulating knob is arranged on the surface. The inner surface of the gripper body is provided with a guide screw, and the floating slider and the inner wall of the gripper body are the gap mates and the inner surface of the cone hole is fixedly connected with the elastic sleeve.

Before use, the chalk can be placed in the floating slider cone-hole elastic sleeve, the floating slider will be pushed forward in the action of spring tension. Adjustment knob and the straight groove fit on the floating slide play the role of fixed locking. Through adjusting the tightness of the knob to control the speed of the floating slider. The guide screw and the guiding groove of the floating slide play a guiding role, thus realizing the function of chalk sticking out automatically when writing, so as to facilitate writing on the blackboard.

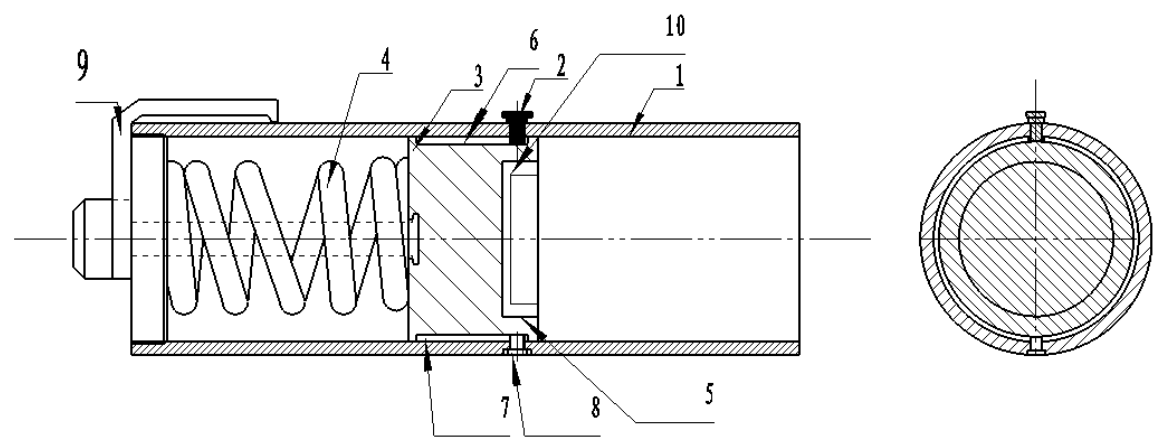

Figure 1 Automatic Chalk holder structure diagram

\section{Usage Instruction of Automatic Chalk Holder}

When writing on the blackboard with a chalk holder, the chalk should be placed in the floating slider cone-hole elastic sleeve first, the floating slider will be pushed forward in the action of spring tension. Adjustment knob and the straight groove fit on the floating slide play the role of fixed locking. Through adjusting the tightness of the knob to control the speed of the floating slider. The guide screw and the guiding groove of the floating slide play a guiding role, thus realizing the function of chalk sticking out automatically when writing, so as to facilitate writing on the blackboard. When a piece of chalk has been used, completely loose the adjustment knob, the floating slider will be pushed to the exit of the gripper bod by the spring tension. Remove the remaining chalk head in the cone hole and replace it with a new chalk. Then push the floating slider back to the gripper body, control the floating speed of the sliding block by adjusting the tension of the adjustment knob. The setting of the elastic sleeve at the cone hole makes it easy to insert fixed chalk. (Fig. 2).

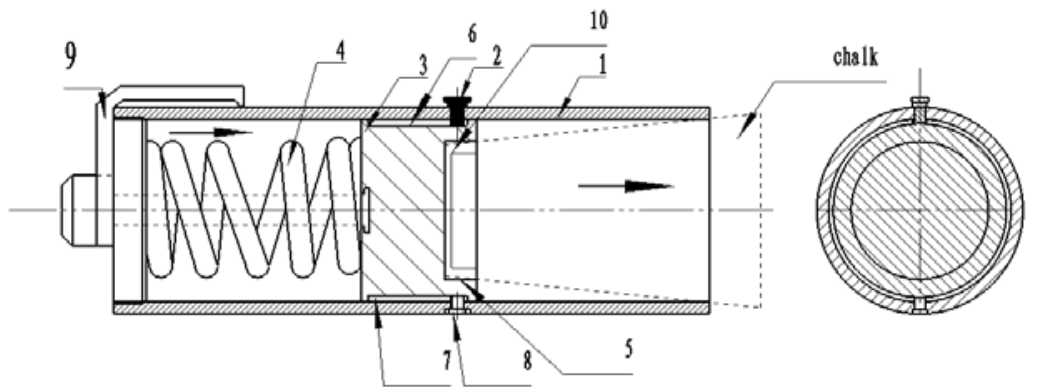

Figure 2 Usage instruction of automatic chalk holder 
When no chalk is used, the adjustment knob 2 can be adjusted to tighten, limiting the reach of the floating slider 3 . Use wear clip 9 to place the chalk holder in clothing, books and other portable areas (Fig. 3)

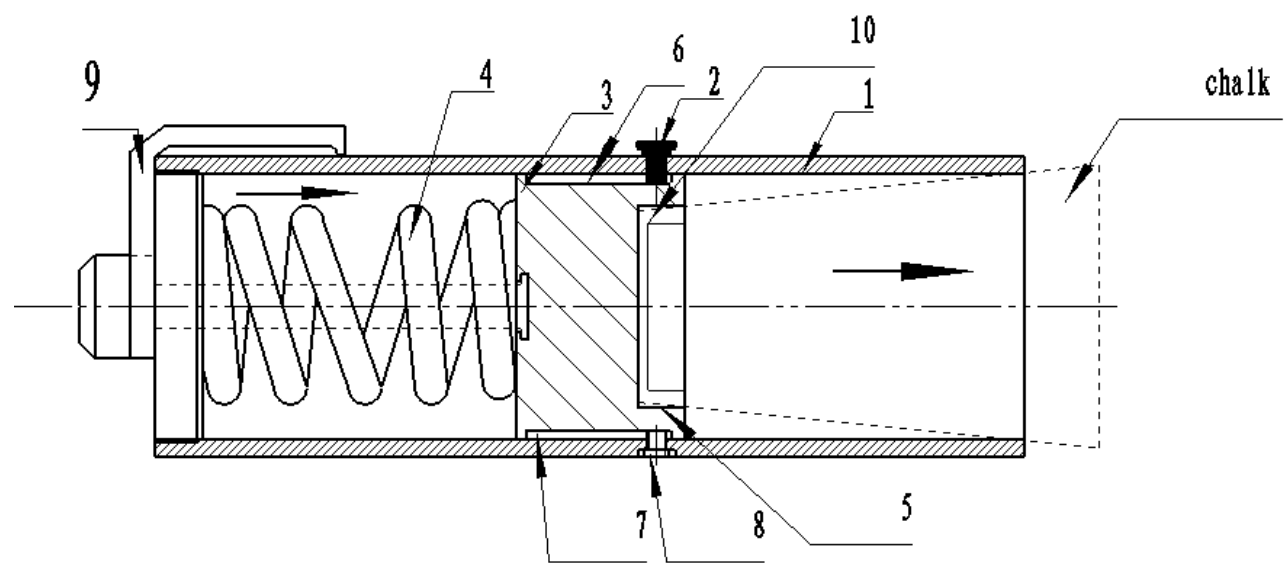

Figure 3 Automatic Chalk holder carrying diagram

\section{Conclusion}

The automatic chalk holder has been used in the field repeatedly, which proves that the chalk holder is smooth and stable in the process of use, the clamping is reliable and the mechanism is in good coordination. The automatic chalk holder is validated by production and quality inspection, it can avoid chalk dust on the hands when teachers write on the blackboard and protect the skin on the teacher's hands. The setting of the spring can solve the waste problem that caused by broken chalk, which often happens when teachers write in different strength. The practice proves that the chalk holder has the features of simple structure, safe to use, easy to make, low in cost and easy and flexible in clamping. The automatic chalk holder can realize the function of automatic pen-out while writing. It saves time and labor and has certain popularization significance.

\section{References}

[1] Robert Joton, Mechanical Design [M]. Mechanical Industry Press, 2016.

[2] Chen Hongjun, Practical Machining Process Manual [M]. Mechanical Industry Press, 2016.

[3] Liu Ying, Mechanical Parts Structure Design and Calculation Example [M]. Chemical Industry Press, 2015.

[4] Amritsar, Mechanical Design Parts and Utility Atlas [M]. Mechanical Industry Press, 2013.

[5] Zhang Exhibition, Practical Mechanical Transmission Design Handbook [M]. Mechanical Industry Press, 2012. 